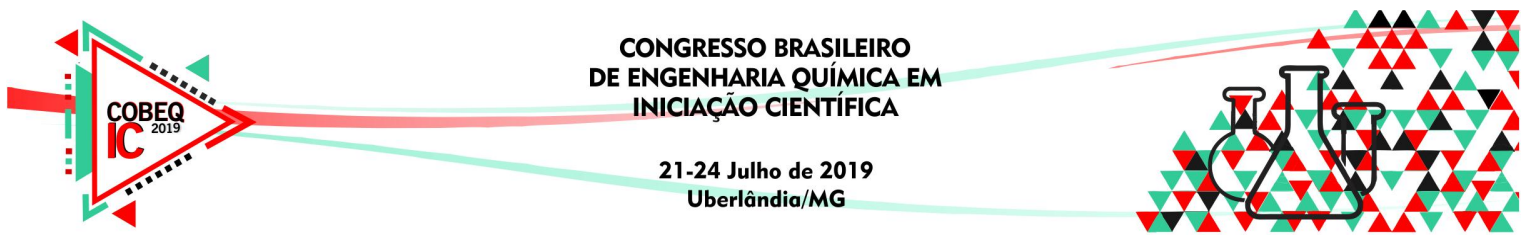

\title{
CARACTERIZAÇÃO DA ÁGUA DE LAVAGEM E DO LODO DO DECANTADOR DE UMA ESTAÇÃO DE TRATAMENTO DE ÁGUA
}

\author{
SERAFIM E.Z.C. ${ }^{1}$, DAMASCENO B.M. ${ }^{1}$, BELLIDO J.A. ${ }^{2}$, MELGAR L.Z. ${ }^{2}$, SANTOS \\ E.P.C.C. ${ }^{3}$ \\ ${ }^{1}$ Universidade Federal de São João Del-Rei, Engenharia Civil \\ ${ }^{2}$ Universidade de São João Del-Rei, Departamento de Engenharia Química \\ ${ }^{3}$ Universidade de São João Del-Rei, Departamento de Tecnologia em Engenharia de Civil, \\ computação e humanidades \\ E-mail para contato: eliane.santos@ufsj.edu.br
}

\begin{abstract}
RESUMO - No presente trabalho foi realizado um estudo em uma estação de tratamento de água na região do Campus Alto Paraopeba/Minas Gerais, visando caracterizar, por meio dos parâmetros Demanda Química de Oxigênio (DQO), Demanda Bioquímica de Oxigênio (DBO) e sólidos, o lodo gerado tanto no decantador, quanto na água de lavagem. Para caracterizar os resíduos gerados foram coletadas quatorze amostras da água lavagem dos filtros e do lodo do decantador ao longo dos meses de março a novembro de 2018. Pôde-se verificar durante o estudo que os valores de DBO do lodo do decantador variaram de 8,58 a $65,38 \mathrm{mg} . \mathrm{L}^{-1} \mathrm{e}$ os resultados de DBO obtidos da água de lavagem do filtro variaram 0,50 a $2,13 \mathrm{mg} \cdot \mathrm{L}^{-1}$. De acordo com a Deliberação Normativa COPAM/CERH-MG/2008 MG No 1/2008, a água de lavagem poderia ser lançada sem tratamento, pois o limite máximo para lançamento é de $60 \mathrm{mg} . \mathrm{L}^{-1}$ e os valores encontrados foram inferiores. Já os valores de DQO do lodo do decantador variaram aproximadamente de 50 a $1500 \mathrm{mg} \cdot \mathrm{L}^{-1}$ e os valores de DQO obtidos da água de lavagem do filtro variaram aproximadamente 6,0 a $350 \mathrm{mg} \cdot \mathrm{L}^{-1}$. De acordo com a Deliberação Normativa COPAM/CERH-MG/2008 o valor máximo permitido para lançamento é de $180 \mathrm{mg} \cdot \mathrm{L}^{-1}$. Diante dos resultados obtidos dos parâmetros analisados percebe-se claramente a necessidade de se fazer algum tipo de tratamento no efluente gerado durante o tratamento de água antes lança-lo corpo d'água, a fim de proteger o meio ambiente.
\end{abstract}

\section{INTRODUÇÃO}

A água é um bem de domínio público e um recurso natural limitado. A Lei 9.433/1997, conhecida como Lei das Águas, veio para garantir à atual e às futuras gerações disponibilidade de água, em padrões de qualidade adequados aos devidos usos, regulamentando o lançamento de efluentes nos corpos d'água de maneira a reduzir os impactos ambientais.

Segundo Tucci, Hespanhol e Netto (2001), as características da água dependem das condições geológicas e geomorfológicas e da cobertura vegetal da bacia de drenagem e 


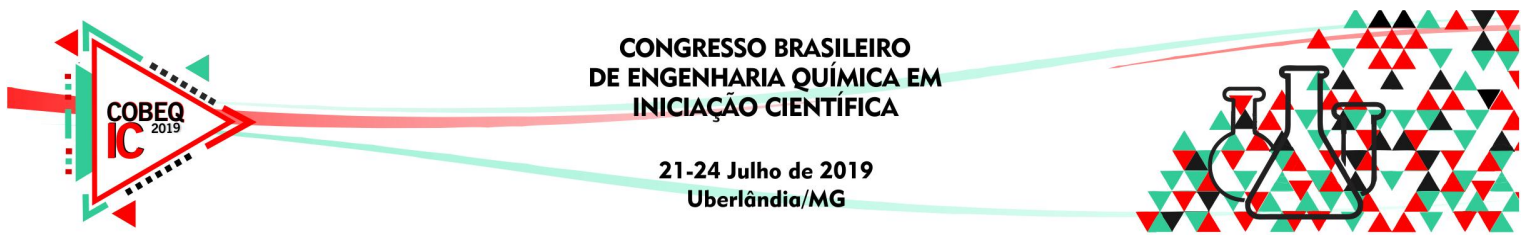

também do comportamento dos ecossistemas terrestres e das ações do homem. Entre as ações humanas que mais podem influenciar na qualidade da água pode citar: (a) lançamento de cargas nos sistemas hídricos, (b) alteração do uso do solo rural e urbano e (c) modificações no sistema fluvial.

O Programa Nacional de Vigilância da Qualidade da Água para Consumo Humano criado pelo Ministério da Saúde consiste em um conjunto de ações adotadas continuamente pelas autoridades de saúde pública para garantir à população o acesso à água em quantidade suficiente e qualidade compatível com o padrão de potabilidade estabelecido na legislação vigente, como parte integrante das ações de promoção da saúde e prevenção dos agravos transmitidos pela água (MINISTÉRIO DA SAÚDE, 2011). Contudo, quando se faz o tratamento da água há formação de resíduos independentemente da técnica de tratamento utilizada e esses resíduos devem ser tratados, a fim de se proteger o meio ambiente e atender à legislação vigente, quais sejam: Resolução do CONAMA N 357/2005, Resolução CONAMA No 430/2011, Resolução COPAM/CERH-MG N 1/2008 e Resolução CONAMA n²37/1997.

É fundamental que os resíduos gerados nas ETAs sejam tratados de forma apropriada, pois o descarte inadequado pode acarretar impactos ambientais, como a contaminação do solo e dos corpos d'água. Esses impactos podem trazer consequências à fauna, à flora e ao próprio homem (ACHON, BARROSO E CORDEIRO, 2013).

Embora, atualmente, a construção de um sistema de abastecimento de água não possa ser realizada sem as licenças ambientais, a maioria das estações construídas anteriormente a essas Resoluções tratam a água, contudo, ainda não conseguiram se adequar às exigências da legislação em vigor, ou seja, ainda lançam os resíduos sem tratamento em corpos de água ou dão outros destinos. Essas estações não foram projetadas para terem seus resíduos recolhidos e tratados e em muitas delas não há sequer áreas disponíveis para a implantação de uma estação de tratamento de resíduos. Outro problema é a falta de conhecimento tanto das características quanto da quantidade de resíduos que são gerados durante o tratamento de água, o que dificulta a escolha do tratamento mais adequado para os resíduos (ACHON, BARROSO E CORDEIRO 2013).

No estado de Minas Gerais, segundo dados do Ministério Público Federal (2009), de 175 municípios avaliados, apenas $3 \%$ possuem unidade de tratamento de resíduos para tratar o lodo gerado durante o tratamento de água e $87 \%$ lançam o lodo gerado em corpos de água. Os demais municípios avaliados dão aos resíduos outro destino.

O lodo originado do tratamento de água consiste das impurezas contidas na água do manancial, ou seja, os microrganismos, os sólidos orgânicos e não orgânicos e os sólidos originados dos coagulantes e de outros produtos utilizados para tratar a água e não devem ser lançados em corpos d'água sem tratamento.

Como pode ser observado, em Minas Gerais a maior parte das estações de tratamento ainda descartam seus resíduos sem tratamento. Conhecer as características desses resíduos é fundamental para a definição das possíveis técnicas de tratamento.

Diante disso, no presente trabalho foi realizado um estudo em uma estação de tratamento de água na região próxima ao Campus Alto Paraopeba/Minas Gerais, visando 


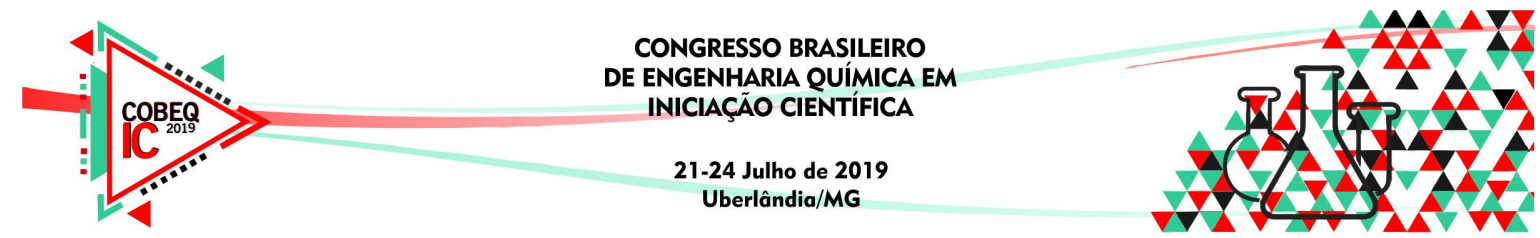

caracterizar, por meio dos parâmetros $\mathrm{DBO}$, DQO e sólidos, o lodo gerado tanto no decantador, quanto na água de lavagem.

\section{METODOLOGIA}

Para caracterizar os resíduos gerados durante o tratamento da água foram coletadas quatorze amostras da água de lavagem dos filtros e do lodo do decantador ao longo dos meses de março a novembro de 2018, de uma estação de tratamento de água - ETA que trata a água por ciclo completo e está localizada na região do Alto Paraopeba, em Minas Gerais.

Foram analisados os seguintes parâmetros: sólidos, Demanda Química de Oxigênio (DQO) e Demanda Bioquímica de Oxigênio (DBO).

As análises foram realizadas em triplicatas no Laboratório de Hidráulica e Saneamento da Universidade Federal de São João del-Rei - Campus Alto Paraopeba e executadas obedecendo as determinações do Standard Methods for the Examination of Water and Wastewater (AMERICAN PUBLIC HEALTH ASSOCIATION, 2005).

Os equipamentos utilizados nas análises, assim como as suas respectivas finalidades, encontram-se na Tabela 1.

Tabela 1 - Equipamentos utilizados

\begin{tabular}{|l|l|}
\hline \multicolumn{1}{|c|}{ Equipamento } & \multicolumn{1}{|c|}{ Finalidade } \\
\hline Espectrofotômetro Gehaka Modelo VIS 200G & Análise de DQO \\
\hline $\begin{array}{l}\text { Medidor de Oxigênio Dissolvido de Bolso à Prova } \\
\text { d'Água - DO Eco }\end{array}$ & $\begin{array}{l}\text { Análise de oxigênio dissolvido e } \\
\text { DBO }\end{array}$ \\
\hline pHmetro Digimed DM22 & Medir do pH \\
\hline Reator de DQO & Digestão do composto \\
\hline Turbidímetro Digital Portátil Digimed - uT & Análise de turbidez \\
\hline Vórtex & $\begin{array}{l}\text { Homogeneização do composto } \\
\text { de DQO }\end{array}$ \\
\hline
\end{tabular}

\section{RESULTADOS}

As Figuras 1 e 2 apresentam os resultados de DBO obtidos nas análises para as amostras de lodo do decantador (LD) e para a água de lavagem dos filtros (AL). Vale ressaltar que o números do eixo $\mathrm{x}$ se referem aos números de amostras. Notou-se que a DBO do lodo do decantador variou de 8,58 a $65,38 \mathrm{mg} \cdot \mathrm{L}^{-1}$ e os resultados de DBO obtidos da água de lavagem do filtro variaram de $0,50 \mathrm{a} 2,13 \mathrm{mg} \cdot \mathrm{L}^{-1}$. 

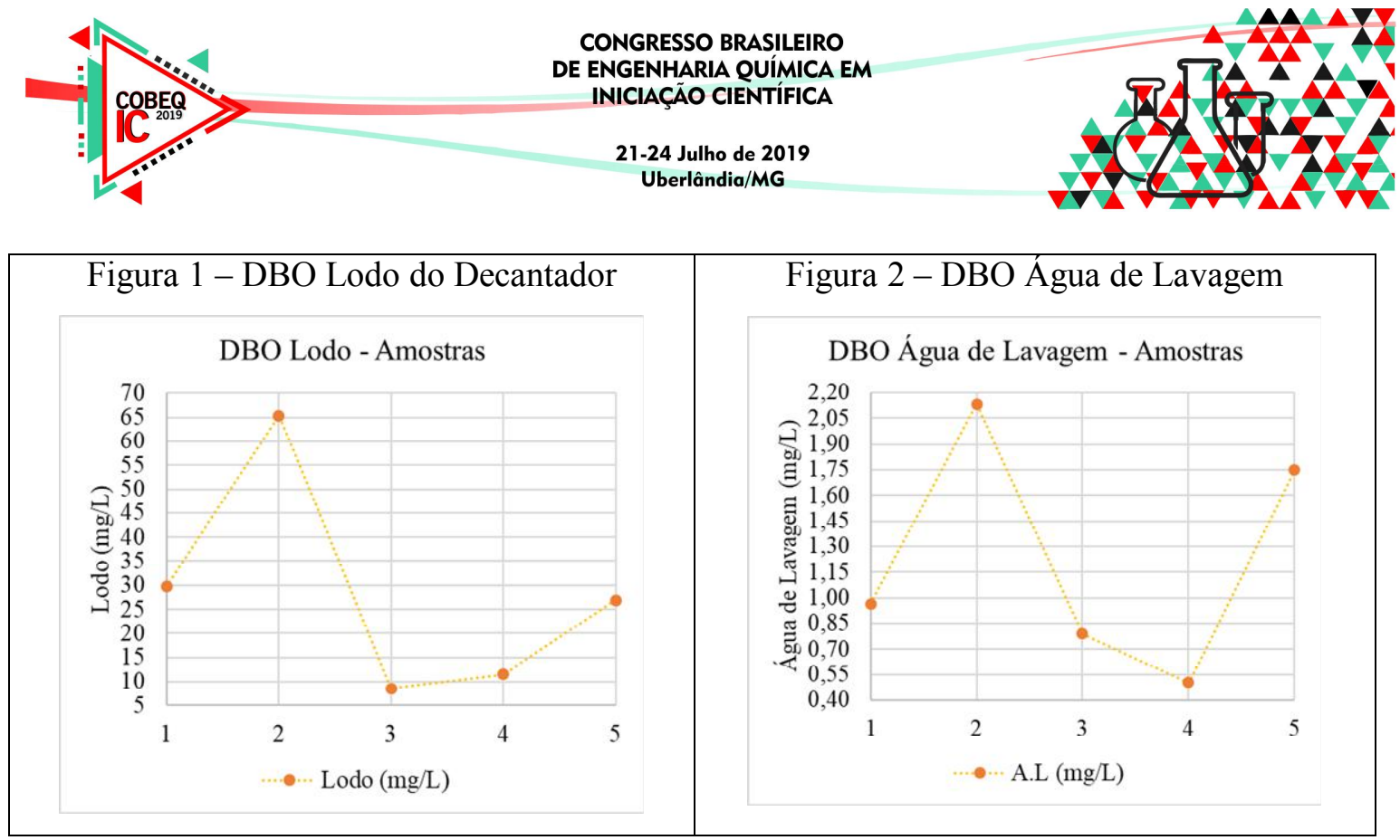

De acordo com a Deliberação Normativa COPAM/CERH-MG/2008, a água de lavagem poderia ser lançada sem tratamento, pois o limite máximo para lançamento é de $60 \mathrm{mg}$. $\mathrm{L}^{-1}$. Já o lodo do decantador apresentou um ponto superior ao estabelecido pela legislação.

As Figuras 3 e 4 apresentam os resultados de DQO obtidos nas análises para as amostras de lodo do decantador e para a água de lavagem dos filtros. Notou-se que a DQO do lodo do decantador variou de aproximadamente 50 a $1500 \mathrm{mg} \cdot \mathrm{L}^{-1}$ e os valores de DQO obtidos da água de lavagem do filtro variaram de aproximadamente 6,0 a $350 \mathrm{mg} \cdot \mathrm{L}^{-1}$.

De acordo com a Deliberação Normativa COPAM/CERH-MG/2008, o valor máximo permitido para lançamento de DQO é de $180 \mathrm{mg} \cdot \mathrm{L}^{-1}$ ou a) tratamento com eficiência de redução de DQO em no mínimo 55\% e média anual igual ou superior a $65 \%$ para sistemas de esgotos sanitários e de percolados de aterros sanitários municipais; b) tratamento com eficiência para a redução de DQO em no mínimo $70 \%$ e média anual igual ou superior a $75 \%$ para os demais sistemas.

Embora a maior parte das amostras analisadas para a água de lavagem tenham tido valores menores que o exigido pela legislação, recomenda-se que seja realizado algum tipo de tratamento, pois houve dias em que o efluente apresentou valores de DQO maiores que o exigido pela legislação.

Comparando os valores de DQO e o de DBO, observa-se que o lodo tem um caráter mais químico do que biológico. Assim um tratamento físico-químico seria mais recomendado para tratá-lo. 


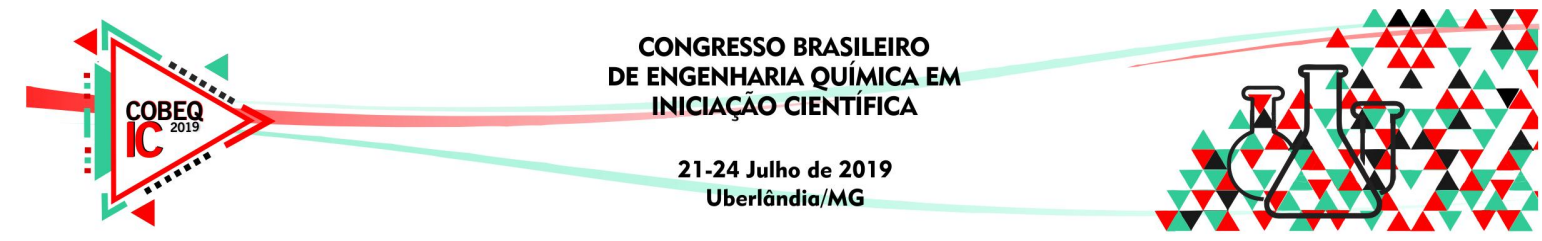

Figura 3 - DQO Lodo do Decantador

Figura 4 - DQO Água de Lavagem

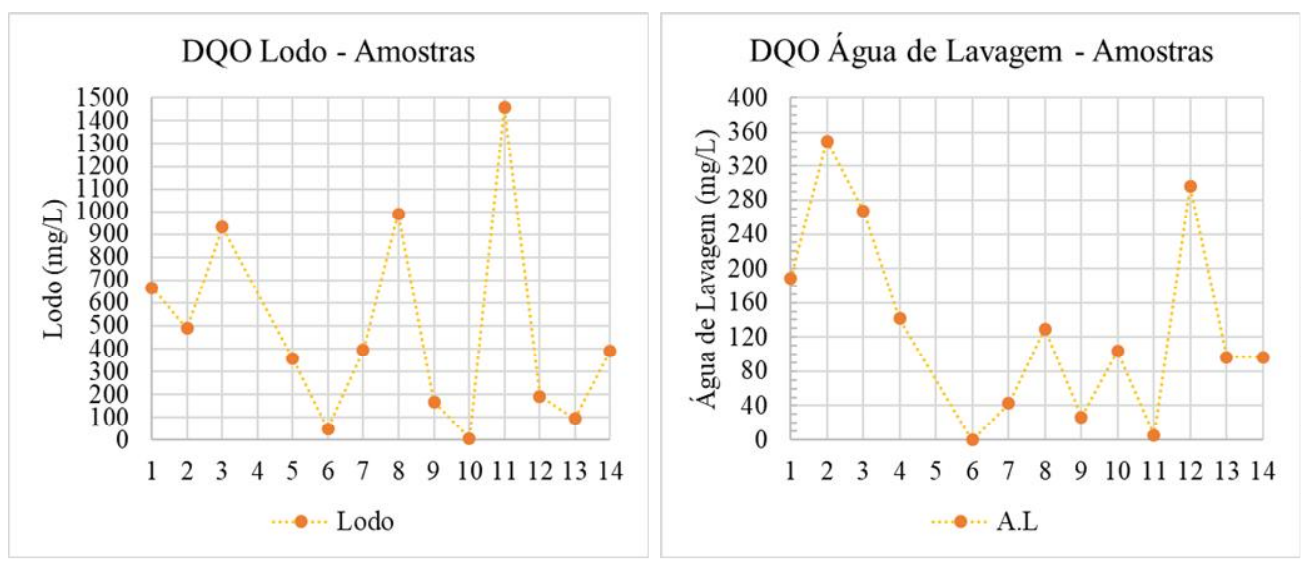

Os valores de sólidos totais (ST), sólidos totais fixos (STF) e sólidos totais voláteis (STV) obtidos para as amostras de água de lavagem dos filtros estão apresentadas na Figura 5.

Os valores para a série de sólidos totais das amostras de água de lavagem dos filtros, mostrados na Figura 5, apresentaram as seguintes variações: 95,56 a 417,78 mg. $\mathrm{L}^{-1}$, para ST; 46,67 a $307,78 \mathrm{mg} . \mathrm{L}^{-1}$ para STF; e 17,78 a $110,00 \mathrm{mg} . \mathrm{L}^{-1}$ para STV.

A Figura 6 mostra os valores observados para a série de sólidos para o lodo do decantador. Observaram-se as seguintes variações: 238,89 a $14.596,67$ mg. $\mathrm{L}^{-1}$ para ST; 134,44 a $10.783,33 \mathrm{mg} . \mathrm{L}^{-1}$ para STF; e 34,44 a $3.813,33 \mathrm{mg} . \mathrm{L}^{-1}$ para STV.

Figura 5- Análise de Sólidos da amostra de Água de Lavagem

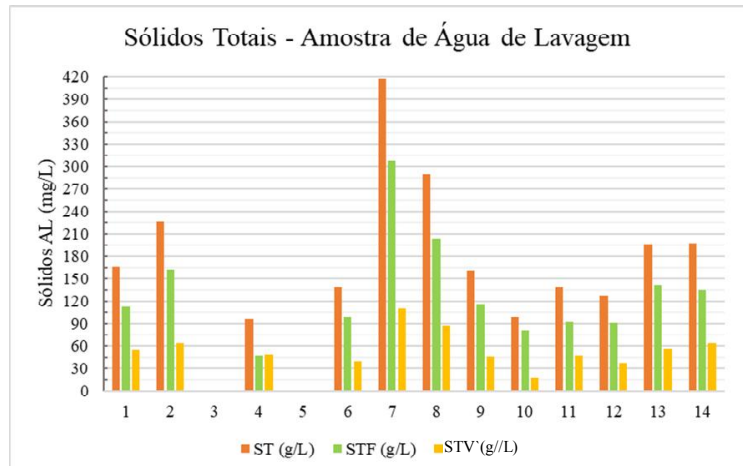

Figura 6 - Análise de Sólidos da amostra de Lodo do Decantador

Vale ressaltar que a legislação fala somente em sólidos totais e que o limite máximo estabelecido é de $100 \mathrm{mg} . \mathrm{L}^{-1}$. Todos os valores obtidos de ST para o lodo do decantador ficaram acima do que é estabelecido pelo COPAM, sendo necessário algum tratamento antes de ser lançado no corpo d'água. 


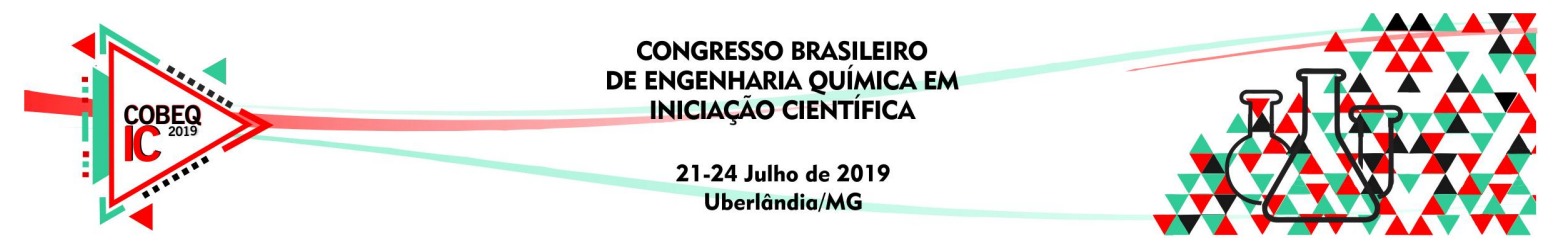

\section{CONCLUSÃO}

Pôde-se verificar durante o estudo que os valores de DBO do lodo do decantador variaram de 8,58 a $65,38 \mathrm{mg} . \mathrm{L}^{-1} \mathrm{e}$ os resultados de DBO obtidos da água de lavagem do filtro variaram 0,50 a $2,13 \mathrm{mg} \cdot \mathrm{L}^{-1}$. De acordo com a Deliberação Normativa COPAM/CERH$\mathrm{MG} / 2008$, a água de lavagem poderia ser lançada sem tratamento, pois o limite máximo para lançamento é de $60 \mathrm{mg} . \mathrm{L}^{-1} \mathrm{e}$ os valores encontrados foram inferiores.

Já os valores de DQO do lodo do decantador variaram aproximadamente de 50 a 1500 $\mathrm{mg} \cdot \mathrm{L}^{-1}$ e os valores de DQO obtidos da água de lavagem do filtro variaram aproximadamente 6,0 a $350 \mathrm{mg} \cdot \mathrm{L}^{-1}$. De acordo com a Deliberação Normativa COPAM/CERH-MG 001/2008 o valor máximo permitido para lançamento é de $180 \mathrm{mg} \cdot \mathrm{L}^{-1}$. Observa-se que os valores encontrados ficaram muito acima do recomendo pela legislação.

Todos os valores de ST obtidos para o lodo do decantador ficaram acima do que é estabelecido pelo COPAM, que é de $100 \mathrm{mg} \cdot \mathrm{L}^{-1}$.

Diante dos resultados obtidos dos parâmetros analisados percebe-se claramente a necessidade de se fazer algum tipo de tratamento no efluente gerado durante o tratamento de água antes de lançá-lo no corpo d'água, a fim de proteger o meio ambiente.

\section{REFERÊNCIAS BIBLIOGRÁFICAS}

ACHON, C.L.; BARROSO, M. M; CORDEIRO, J.S. (2013). Resíduos de estações de tratamento de água e a ISO 24512: desafio do saneamento brasileiro. Revista Engenharia Sanitária e Ambiental, ISSN 1413-4152, vol. 18, nº.2, Rio de Janeiro, abril/junho 2013.

CONAMA - Conselho Nacional do Meio Ambiente, 2011. Resolução nº430 de 13 de maio de 2011. Diário Oficial da União nº 92, de 15 maio 2017.

Deliberação Normativa Conjunta COPAM/CERH-MG No 1, de 05 de maio de 2008. Disponível online em: http://www.mma.gov.br/port/conama/processos/EFABF603/DeliberaNormativaConjunt a COPAM-CERHno01-2008.pdf Acesso em janeiro, 2019.

TUCCI, C.E.M., HESPANHOL, I. e NETTO, O.M.C. Gestão da água no Brasil. Brasília: UNESCO, 156p, 2001.

MINISTÉRIO DA SAÚDE. Portaria Consolidada $\mathrm{n}^{\mathrm{o}}$ 5, de 28 de setembro de 2017. Consolidação das normas sobre as ações e os serviços de saúde do Sistema Único de Saúde. Diário Oficial da União nº 190, de 3 outubro 2017. 